\title{
Acetaminophen and Asthma
}

\section{Victoria W Persky}

The article by Perzanowski et al in this issue of Thorax (see page 118) adds one more piece of evidence supporting a possible role for acetaminophen in the development of asthma in children. ${ }^{1}$ Five previous studies, including three prenatal prospective cohorts, ${ }^{2-5}$ have suggested that in utero ingestion of acetaminophen may increase the risk of asthma and respiratory symptoms in children. ${ }^{2-7}$ Increased risk of asthma from postnatal use of acetaminophen is also suggested by reports of children ${ }^{8-12}$ and adults. ${ }^{8} 13-17$ The possibility that acetaminophen may contribute to the development of asthma is supported by parallel time trends in dramatic increases in use of the medication in response to reports of associations of aspirin use with Reye syndrome $e^{18-20}$ and increases in asthma prevalence between the mid 1970s and mid 1990s. ${ }^{21}$

There is also biological plausibility. Acetaminophen, ${ }^{22-24}$ as well as one of its metabolites, the highly reactive $N$-acetyl $-p$ benzoquinoneimine, ${ }^{23}$ has been associated with decreased glutathione. There is substantial literature documenting the antioxidant capacity of glutathione $e^{25}$ as well as the role of reactive oxygen species in asthma morbidity. ${ }^{26}$ In addition, decreased glutathione may affect the development of asthma by altering antigen recognition towards favouring $\mathrm{T}$ helper 2 (Th2) over Th1 cytokines. ${ }^{23} 27$ Other, less likely, possibilities relate to decreased suppression of cyclo-oxygenase or direct antigenicity of acetaminophen. $^{23}$

The study by Perzanowski et al notes that associations of prenatal acetaminophen use with asthma are present only in those with the minor allele variant (Ile/ $\mathrm{Val}$ or $\mathrm{Val} / \mathrm{Val}$ ) in the glutathione $S$-transferase P1 gene (GSTP1). ${ }^{1}$ There is an increasing body of literature suggesting that GST alleles may modulate environmental effects on asthma through altered ability to detoxify compounds. ${ }^{28}$ Three genotypes that have been explored in some detail are GSTM1, GSTT1 and GSTP1. Null variants of GSTM1 and GSTT1 and the minor alleles of GSTP1 (with valine at amino acid

Correspondence to Dr Victoria W Persky, Division of Epidemiology and Biostatistics, University of Illinois at Chicago School of Public Health, Chicago IL 60612, USA; vwpersky@uic.edu position 105) have shown protective effects in some $e^{29-32}$ but not all ${ }^{33-35}$ studies. GSTP is more prevalent in the lung than other GSTs and catalyses conjugation of glutathione to secondary oxidation products. $^{2533}$ Gilliland noted that children with the GSTM1 null variant and GSTP1 Val105 had slower lung growth ${ }^{29}$ but that children homozygous for the GSTP1 Val105 variant, rather than being at increased risk, were at lower risk of respiratory illness. ${ }^{34}$ Similarly, in another report, Gilliland noted that adults exposed to GSTP1 Val105 alleles were at lower risk of allergic response to second-hand tobacco smoke. ${ }^{35}$ In addition to the current study there are two other large prospective birth cohorts showing increased effects of air pollution on atopy ${ }^{31}$ and persistent wheeze ${ }^{32}$ in children with the GSTP1 Val105 alleles. Others have shown associations of this allele with severity of disease. $^{36}$ Romieu and her group have a series of reports from a trial in Mexico in which effects of ozone exposure on lung function and inflammatory responses were modified by antioxidant supplementation and the presence of the GSTM1 null allele. ${ }^{30} 37-39$ The fact that findings are more consistent for modulation of environmental exposures than for direct effects of GST alleles suggests that the genetic variations are operative through detoxification of specific contaminants.

The growing literature relating acetaminophen with respiratory conditions must be viewed with some caution. There is always the risk of confounding by conditions leading to the use of the medication. Although Perzanowski's study did not examine indications of use, the investigators did look at antibiotic use and did not find an association with acetaminophen; nor did they find that antibiotic use confounded the results. ${ }^{1}$ Similarly, the fact that pain was the main reason for acetaminophen use in the Danish study and that adjustment for indication of use did not affect the results suggests that the findings are not the indirect result of infections. ${ }^{5}$ In addition, although use of aspirin and other non-steroidal inflammatory medicine in these studies was low, in larger cohorts with sufficient numbers of participants similar effects were not seen with the other analgesics, ${ }^{5}$ and a rando- mised trial in children with asthma found significantly lower risk of outpatient visits for asthma in those randomised to ibuprofen versus acetaminophen. ${ }^{9}$

The lack of consistency among studies regarding timing of use in pregnancy has implications for biological plausibility. The current study found similar associations throughout pregnancy that were not significant in the first trimester. ${ }^{1}$ Two of the three previous prospective cohorts noted stronger effects towards the end of the pregnancy, ${ }^{2-4}$ while the large Danish cohort noted stronger effects with use earlier in gestation. ${ }^{5}$ It has been suggested that the fetal liver is not able to metabolise acetaminophen early in pregnancy to $N$ acetyl-p-benzoquinoneimine. ${ }^{2-4} 40$ Effects from use in the first trimester would therefore imply other mechanisms related to GSTP1 genotypes.

Loss to follow-up and the fact that the relationships reached significance only in year 5 in this study is of some concern. In other cohorts the effects were seen at younger ages. $^{2-5}$ The follow-up of this cohort is $<69 \%$ suggested-301 of the original 714 -and there could be biases inherent in the drop-out rate. Reassuring is the fact that there were no differences in reported acetaminophen use in those who did and did not remain in the study. The authors indicate, however, that follow-up was greater among Hispanics - there could have been other factors related to acetaminophen use, follow-up and diagnosis of asthma, such as differential prenatal and postnatal care, that could have affected the results.

Imprecise measures of dose and frequency could also account for some of the differences among studies. The study of Perzanowski et al found a significant dose response with days of use. Increased frequency had stronger associations in one, ${ }^{2}{ }^{3}$ but not another, study, ${ }^{5}$ in which frequency of use was available. Data on medication use in all these studies, however, were not obtained by diaries and do not allow careful quantification of use. The lack of precision, however, should bias towards the null hypothesis, and, while contributing to differences among studies, could not account for the general consistency in overall results.

As is often the case, this paper in the context of emerging literature raises as many questions as it answers. If the effects seen are related to modulation of antioxidant defences can they be reversed, as shown by Romieu's group, with adequate nutrition? Are we comfortable changing our current recommendations of use of 
anti-inflammatory medication? It was estimated that in 2004, 65\% of women took acetaminophen in pregnancy, with $18 \%$ taking ibuprofen and 4\% taking aspirin. ${ }^{20}$ A shift from acetaminophen to ibuprofen might have other associated risks. ${ }^{41}$ Can we justify a randomised controlled trial of acetaminophen versus other anti-inflammatories with and without antioxidant supplementation? Would a safer course perhaps be increased efforts at pollution control and continued recommendations to limit all medication in pregnancy? Finally, it is important to continue research in the area with animal models and more precise measures of the amount and timing of exposure, possible confounding associated symptoms, and benefit versus risk assessments of alternative approaches.

Competing interests None.

Provenance and peer review Commissioned; not externally peer reviewed.

Thorax 2010;65:99-100.

doi:10.1136/thx.2009.127977

\section{REFERENCES}

1. Perzanowski MS, Miller RL, Tang D, et al. Prenatal acetaminophen exposure and risk of wheeze at age 5 years in an urban, low income cohort. Thorax 2010;65:118-23.

2. Shaheen So, Newson RB, Sheriff A, et al. ALSPAC Study Team. Paracetamol exposure and wheezing in early childhood. Thorax 2002;57:958-73.

3. Shaheen So, Newson RB, Henderson AJ, et al. ALSPAC Study Team. Prenatal paracetamol exposure and risk of asthma and elevated immunoglobulin $E$ in childhood. Clin Exp Allergy 2005;35:18-25.

4. Persky V, Piorkowski J, Hernandez E, et al. Prenatal exposure to acetaminophen and respiratory symptoms in the first year of life. Ann Allergy Asthma Immunol 2008;101:271-8.

5. Redordosa C, Kogevinas M, Sorensen HT, et al. Pre-natal exposure to paracetamol and risk of wheezing and asthma in children: a birth cohort study. Int J Epidemiol 2008;37:583-90.

6. Garcia-Marcos L, Sanchez-Solis M, PerezFernandez V, et al. Is the effect of prenatal paracetamol exposure on wheezing in preschool children modified by asthma in the mother? Int Arch Allergy Immunol 2009;149:33-7.

7. Koniman R, Chan $\mathrm{YH}$, Tan $\mathrm{TN}$, et al. A matched patient-sibling study on the usage of paracetamol and the subsequent development of allergy and asthma. Pediatr Allergy Immunol 2007;18:128-34.

8. Davey G, Berhane $Y$, Duncan P, et al. Use of acetaminophen and the risk of self-reported allergic symptoms and skin sensitization in Butajira, Ethiopia. J Allergy Clin Immunol 2005;116:863-8.
9. Lesko SM, Louik C, Vezina RM, et al. Asthma morbidity after the short-term use of ibuprofen in children. Pediatrics 2002;109:e20.

10. Cohet C, Cheng S, MacDonald C, et al. Infections, medication use, and the prevalence of symptoms of asthma, rhinitis, and eczema in childhood. J Epidemiol Community Health 2004;58:852-7.

11. Beasley R, Clayton T, Crane J, et al. for the ISAAC Phase Three Study Group. Association between paracetamol use in infancy and childhood, and risk of asthma, rhinoconjunctivitis, and eczema in children aged 6-7 year: analysis from phase three of the ISAAC programme. Lancet 2008;372:1039-48.

12. Garcia E, Aristizabal G, Vasquez C, et al. Prevalence of and factors associated with current asthma symptoms in school children 6-7 and 13-14 yr old in Bogota, Columbia. Pediatr Allergy Immunol

2008:19:307-14.

13. Shaheen So, Sterne JA, Songhurst CE, et al. Frequent paracetamol use and asthma in adults. Thorax 2000;55:266-70.

14. Shaheen $\mathbf{S}$, Potts J, Gnatiuc L, et al. The relation between paracetamol use and asthma: a GA ${ }^{2}$ LEN European case-control study. Eur Respir J 2008; 32:1231-6

15. Thomsen SF, Kyvik KO, Skadhauge L, et al. Intake of paracetamol and risk of asthma in adults. J Asthma 2008;45:675-6.

16. Barr RG, Wentowski CC, Curhan GC, et al. Prospective study of acetaminophen use and newly diagnosed asthma among women. Am J Respir Crit Care Med 2004;169:836-41.

17. McKeever TM, Lewis SA, Smit HA, et al. The association of acetaminophen, aspirin, and ibuprofen with respiratory disease and lung function. $A m \mathrm{~J}$ Respir Crit Care Med 2005;171:966-71.

18. Arrowsmith JB, Kennedy DL, Kuritsky JN, et al. National patterns of aspirin use and Reye syndrome reporting, United States, 1980 to 1985. Pediatrics 1987:79:858-63.

19. Porter JDH, Robinson PH, Glasgow JFT, et al. Trends in the incidence of Reye's syndrome and the use of aspirin. Arch Dis Child 1990;65:826-9.

20. Werler MM, Mitchell AA, Hernandez-Diaz S, et al. Use of over-the-counter medications during pregnancy. Am J Obstet Gynecol 2005;193:771-7.

21. Moorman JE, Rudd RA, Johnson CA, et al. National surveillance for asthma-United States. 1980-2004. MMWR Morb Mortal Wkly Rep 2007;56:1-54.

22. Kozer E, Evans S, Barr J, et al. Glutathione, glutathione-dependent enzymes and antioxidant status in erythrocytes from children treated with highdose paracetamol. Br J Clin Pharmacol 2003:55:234-40.

23. Eneli I, Sadri K, Camargo C Jr, et al. Acetaminophen and the risk of asthma. Chest 2005;127:604-12.

24. Dimova S, Hoet PHM, Dinsdale D, et al. Acetaminophen decreases intracellular glutathione levels and modulates cytokine production in human alveolar macrophages and type II pneumocytes in vitro. Int J Biochem Cell Biol 2005;37:1727-37.

25. Rahman I. Regulation of glutathione in inflammation and chronic lung diseases. Mutat Res 2005:579:58-80.

26. Mak JCW, Chan-Yeung MMW. Reactive oxidant species in asthma. Curr Opin Pulm Med 2006, 12:7-11.
27. Peterson JD, Herzenberg LA, Vasquez K, et al. Glutathione levels in antigen-presenting cells modulate Th1 versus Th2 response patterns. Proc Natl Acad Sci USA 1998;95:3071-6.

28. Saadat M, Ansari-Lari M. Genetic polymorphism of glutathione-S-transferase T1, M1 and asthma, a metaanalysis of the literature. Pak J Biol Sci 2007:10:4183-9.

29. Gilliland FD, Gauderman WJ, Vora H, et al. Effects of glutathione-S-tranfersase M1, T1 and P1 on childhood lung function growth. Am J Respir Crit Care Med 2002; 166:710-16.

30. Romieu I, Ramirez-Aguilar M, Sienra-Monge JJ, et al GSTM1 and GSTP1 and respiratory health in asthmatic children exposed to ozone. Eur Respir $J$

2006;28:953-9.

31. Melen E, Nyberg F, Lindgren CM, et al. Interactions between glutathione S-transferase P1, tumor necrosis factor and traffic-related air pollution for development of childhood allergic disease. Environ Health Perspect 2008;116:1077-84.

32. Schroer KT, Myers JMB, Ryan PH, et al. Associations between multiple environmental exposures and glutathione S-transferase P1 on persistent wheezing in a birth cohort. J Pediatr 2009;154:401-8.

33. Fryer AA, Bianco A, Hepple M, et al. Polymorphism at the glutathione S-transferase GSTP1 locus. Am J Respir Crit Care Med 2000;161:1437-42.

34. Gilliland FD, Rappaport EB, Berhane K, et al. Effects of glutathione S-transferase P1, M1, and T1 on acute respiratory illness in school children. Am J Respir Crit Care Med 2002;166:346-51.

35. Gilliland FD, Li YF, Gong $\mathrm{H}$, et al. Glutathione $\mathrm{S}$ Transferase M1 and P1 prevent aggravation of allergic response by secondhand smoke. Am J Respir Crit Care Med 2006;174:1335-41.

36. Ercan H, Birben E, Dizdar EA, et al. Oxidative stress and genetic and epidemiologic determinants of oxidant injury in childhood asthma. J Allergy Clin Immunol 2006;118:1097-104.

37. Romieu I, Sienra-Monge JJ, Ramirez-Aguilar M, et al Genetic polymorphism of GSTM1 and antioxidant supplementation influence lung function in relation to ozone exposure in asthma children in Mexico City. Thorax 2004;59:8-10.

38. Sienra-Monge JJ, Ramirez-Aguilar M, MorenoMacias $\mathrm{H}$, et al. Antioxidant supplemenation and nasa inflammatory responses among young asthmatics exposed to high levels of ozone. Clin Exp Immunol 2004;138:317-22.

39. Romieu I, Sienra-Monge JJ, Ramirez-Aguilar M, et al Antioxidant supplementation and lung functions among children with asthma exposed to high levels of air pollutants. Am J Respir Crit Care Med 2002;166:703-9.

40. Miller MS, Juchau MR, Guengerich P, et al. Drug metabolic enzymes in developmental toxicology. Fundam Appl Toxicol 1996;34:165-75.

41. Alano MA, Ngougmna E, Ostrea EM Jr, et al. Analysis of nonsteroidal anti-inflammatory drugs in meconium and its relation to persistent pulmonary hypertension of the newborn. Pediatrics 2001;107:519-23.

42. Burdan F, Szumilo J, Dudka J, et al. Congenital ventricular septal defects and prenatal exposure to cyclooxygenase inhibitors. Braz J Med Biol Res 2006;39:925-34. 